Sigurd Høye (f. 1972) er medisinsk redaktø i Tidsskriftet, forsker ved Antibiotikasenteret for primærmedisin, Avdeling for allmennmedisin, Universitetet i Oslo, og allmennlege.

\section{Ta dette og et det!}

Påsken markerer det dramatiske høydepunktet i kirkeåret og er høytiden der et av kirkens viktigste sakramenter ble innstiftet - nattverden. I den protestantiske norske kirke består nattverden blant annet av følgende: Deltagerne mottar en hvit, sirkelrund og spiselig gjenstand, påtrykt et merke som forteller om produktets opphav. Deltageren inntar produktet per os, men selve virkningsmekanismen er ikke så helt enkel å forstå for brukeren. Alle landets legemiddelforskrivere burde nikke gjenkjennende.

Legemiddelbruk samvarierer med nasjonal - og religiøs - tilhørighet. Antibiotikabruken i tradisjonelt katolske og ortodokse land som Frankrike, Italia og Hellas er dobbelt så høy som i tradisjonelt protestantiske land som Sverige og Norge (1). Antropologen Reginald Deschepper og medarbeidere har unders $ø$ kt holdninger og antibiotikabruk i to nabobyer på hver side av den belgisk-nederlandske grensen (2). I katolskdominerte Belgia kalte deltagerne sine luftveisinfeksjoner for bronkitt og brukte hyppig antibiotika. I protestantiskdominerte Nederland ble tilsvarende plager kalt forkjølelse, og folk var skeptiske til antibiotika. De spekulerer på om dette kan skyldes forskjeller i religiøs tradisjon - i katolisismen spiller ritualer med konkrete objekter en sentral rolle. En pille kan oppfattes som et sekularisert motstykke til sakramentene, som kan sikre frelse. På nederlandsk side kan den protestantiske etikk, som kjennetegnes av selvkontroll og nøysomhet, forklare større tilbakeholdenhet når det gjelder medikamentbruk (2).

Andre forskere har funnet at i land med en høy andel ateister er det et lavt forbruk av antibiotika (3). Selv om andre kulturelle forhold enn konfesjonstilhørighet også kan forklare forskjellene (4), gir eksemplet en god illustrasjon på forholdet mellom religiøsitet og helseatferd.

Helsevesenet har tatt over mange av rollene kirken tidligere hadde. Hvis man åpner for det, kan man se at helsevesenet innehar de fleste av religionens dimensjoner (5): den etiske (lev riktig, så blir du gammel), den dogmatiske (skolemedisinens forklaringsmodeller), den rituelle (konsultasjonens stramme oppbygning, inkludert den kliniske undersøkelsens håndspåleggelse) og den institusjonelle.

I tidligere tider var det kirken som kunne gi svar på de viktigste spørsmålene i livet. Nå er det helse som er viktigst for oss (6). De livsviktige spørsmålene har neppe endret seg, men for folkog overfor hjelperne - sorteres spørsmålene som helse. For god helse betyr ikke kun fravær av feber og hoste og mindre smerte, kortere sykefravær, bedre funksjon og lengre liv. I Helse på norsk viser Per Fugelli \& Benedicte Ingstad at helse minst like mye handler om mening, livskraft og fellesskap (7).

Dette utfordrer alle helsearbeidere. En ambisiøs løsning vil være at legen også på sett og vis fungerer som prest og påtar seg å håndtere alle problemer pasienten presenterer som helserelaterte. Særlig innen allmennmedisinen, som nettopp karakteriseres som usortert, er lege- presten tidvis sett på som ideal. Allmennlegen og antropologen Cecil G. Helman kalte seg «forstadssjaman» (8). Et utvalg allmennleger beskrev rollen som mer lik prestens enn psykoterapeutens (9). Problemet er at legen ikke nødvendigvis har kompetanse eller lyst til å betjene åndelige behov i et multireligiøst samfunn (7).

I allmennmedisinen er det en grunnkompetanse å kunne avdekke hvorfor pasienten oppsøker helsevesenet (10). Uavhengig av hvor mye prest vi klarer eller ønsker å være, bør vi i det minste øve oss i en av prestens grunnkompetanser: $\AA$ avdekke det religiøse utenfor etablert religion - både innen egen institusjon og hos den hjelpsøkende. Hvis ikke, står vi i fare for å fungere som ufrivilllige pastorer i et offentlig frelsesvesen og tilby pasienten steiner når han ber om brød (11). Til og med noe så banalt som en selvbegrensende luftveisinfeksjon kan for den lidende medføre tap av kontroll, skyldfølelse fordi man ikke har passet seg for trekk eller håp om vidunderlig helbredelse. Når vi sier «ta dette og et det» til pasienten, bør vi vite om vi svarer på pasientens behov for frelse eller konvensjonell helse.

I vår tids altomfattende oppfatning av helse er det en dyd av nødvendighet for helsearbeideren å se sin begrensning. Religion må ikke reduseres til helsehjelp, og helse må ikke formidles som religion. Fugelli \& Ingstad mener det ikke er grunnlag for å styrke presten i legen og advarer mot «den ultimate medikalisering»: Å la religionen bli siste offer i medisinens kolonialisering av livsverdenen (7). Hvis legens rolle skal ligne prestens, er det sjelesørgeren heller enn forvalteren av sakramentene vi bør satse på. Og tilsvarende: Hvis konsultasjonen skal være et sekularisert motstykke til et sakrament, er skriftemålet et bedre valg enn nattverden. Potensielt vidunderlige, hvite og runde gjenstander får man gratis i kirken.

\section{Litteratur}

1. European Centre for Disease Prevention and Control. Antimicrobial consumption interactive database (ESAC-Net). http://ecdc.europa.eu/en/healthtopics/ antimicrobial resistance/esac-net-database/Pages/database.aspx (2.3.2016).

2. Deschepper $\bar{R}$, Vander Stichele RH, Haaijer-Ruskamp FM. Cross-cultural differences in lay attitudes and utilisation of antibiotics in a Belgian and a Dutch city. Patient Educ Couns 2002; 48: 161-9.

3. Blommaert A, Marais C, Hens $\mathrm{N}$ et al. Determinants of between-country differences in ambulatory antibiotic use and antibiotic resistance in Europe: a longitudinal observational study. J Antimicrob Chemother 2014; 69: 535-47.

4. Touboul-Lundgren $P$, Jensen S, Drai J et al. Identification of cultural determinants of antibiotic use cited in primary care in Europe: a mixed research synthesis study of integrated design «Culture is all around us». BMC Public Health 2015; 15: 908.

5. Smart N. Dimensions of the Sacred: An Anatomy of the World's Beliefs. Berkeley, CA: University of California Press, 1998

6. OECD. Better Life Index. www.oecdbetterlifeindex.org/responses/\#NOR (1.3.2016).

7. Fugelli P, Ingstad B. Helse på norsk. God helse slik folk ser det. Oslo: Gyldendal, 2009.

8. Helman C. Suburban shaman: a journey through medicine. Cape Town: Double Storey, 2004

9. Nessa J, Schei E, Stensland P. Korleis møter allmennlegane pasientanes livsproblem? Tidsskr Nor Legeforen 2009: 129: 1323-5.

10. Hjortdahl P. Helseproblemer og bruk av helsetjenester i allmennpraksis. I: Hunskaar S, red. Allmennmedisin. Oslo: Gyldendal, 2013

11. Bibelen. Matt 7,9. 